\title{
Status Mutu Air pada Lahan Gambut di Sungai Putat Kota Pontianak Kalimantan Barat
}

\author{
Laili Fitria ${ }^{{ }^{*}}$, Herda Desmaiani ${ }^{2)}$ Marcelina 3) M. Khalid Syafrianto ${ }^{4)}$ Syahrul Khairi ${ }^{5)}$ \\ 1,2, Teknik Lingkungan, ${ }^{3,5}$ Teknik Kimia, ${ }^{4}$ Teknik Pertambangan \\ Universitas Tanjungpura \\ 1 fitria.laili@gmail.com
}

\begin{abstract}
ABSTRAK terhadap Sungai Putat.

Kata Kunci : Gambut, Status Mutu, Sungai.

\section{PENDAHULUAN}

Keberadaan sungai sebagai air permukaan sangat diperlukan bagi kelangsungan kehidupan manusia, antara lain sebagai air baku minum, air baku irigasi pertanian, peternakan, pembangkit listrik, rekreasi, dan sebagainya. Oleh karena itu sudah selayaknya diberikan perhatian yang cukup besar terhadap sungai, khususnya dalam menjaga kualitasnya agar tetap dapat digunakan secara layak dan berkelanjutan (Liu, Zhi Jun, Wller, Donald E., Jordan, Thomas E., Correll, David L., Boomer, 2008). Namun demikian, banyak sungai besar di dunia yang telah tercemar akibat aktivitas manusia (anthropogenic) (Hendrawan, 2005).
\end{abstract}

Keberadaan sungai sebagai air permukaan sangat diperlukan bagi kelangsungan kehidupan manusia, antara lain sebagai air baku minum, air baku irigasi pertanian, peternakan, pembangkit listrik, rekreasi, dan sebagainya. Diketahui juga bahwa PDAM Tirta Khatulistiwa Kota Pontianak belum melayani seluruh penduduk Kota Pontianak. Sehingga masih ada masyarakat yang memenuhi keperluan air bersih menggunakan air sungai/parit yang ada di Kota Pontianak. Di Sungai Putat yang termasuk kawasan gambut, masyarakat masih menggunakan air sungai tersebut sebagai sumber air bersih. Kualitas perairan sungai merupakan suatu cara yang dapat menduga dan mengevaluasi adanya perubahan lingkungan. Tujuan penelitian ini adalah mengetahui status mutu air pada lahan gambut, tepatnya di Sungai Putat. Standar status mutu air yang digunakan adalah air kelas II berdasarkan PP 82 tahun 2001. Pengambilan sample air menggunakan purposive sampling di 3 titik pada Sungai Putat. Analisis status mutu menggunakan metode STORET. Diketahui bahwa status mutu Sungai Putat Kota Pontianak tercemar sedang. Sehingga dibutuhkan pengendalian pencemaran air

Berdasarkan Keputusan Walikota Pontianak Nomor 398/D-CKTRP/Tahun 2015 tentang Penetapan Lokasi Perumahan Kumuh dan Pemukiman Kumuh di Kota Pontianak, Kelurahan Siantan Hilir merupakan salah satu Kelurahan yang termasuk pemukiman kumuh. Melalui observasi lapangan diketahui bahwa di Sungai Putat tidak pernah dilakukan pemeliharaan oleh Dinas PU sehingga ada sedimentasi di beberapa titik. Namun Sungai Putat tetap dijadikan sebagai sumber air bersih bagi masyarakat tepian Sungai Putat.

Tindakan sederhana yang bisa dilakukan untuk

\section{Article History:}

Received: August, 27 th 2019; Accepted: January, $12^{\text {th }} 2020$ ISSN: 2502-5325 (Online) Terakreditasi Peringkat 3 oleh Kementerian Riset, Teknologi dan Pendidikan Tinggi (ARJUNA), berdasarkan Keputusan Direktur Jenderal Penguatan Riset dan Pengembangan No: 23/E/KPT/2019 tanggal 8 Agustus 2019 mengendalikan tingkat pencemaran sungai adalah melakukan monitoring secara kontinu. Monitoring kualitas air yang dilakukan secara konsisten dapat memberikan informasi status mutu dan menjaga ke $\neg$ berlanjutannya bagi ekosistem setempat (Fulazzaky, M.A., Seong, T.W., dan Masirin, 2010).

Beberapa metode monitoring telah banyak dikembangkan di berbagai dunia untuk mengetahui status mutu (kualitas) suatu sumber air. Salah satu metode yang dikembangkan adalah menggunakan pendeka $\neg$ tan metode STORET. Metoda STORET merupakan salah satu metoda untuk menentukan status mutu air yang umum digunakan. Dengan metoda STORET ini dapat diketahui parameter-parameter yang telah memenuhi atau melampaui baku mutu air. Cara untuk menentukan status mutu air adalah dengan menggunakan sistem nilai dari "US-EPA (Environmental Protection Agency)" (Menteri Negara Lingkungan Hidup Republik Indonesia, 2003).

Kualitas perairan sungai merupakan suatu alat yang dapat menduga dan mengevaluasi terjadinya perubahan lingkungan. Kualitas air dari suatu perairan dapat dinyatakan baik apabila telah memenuhi persyaratan yang telah ditentukan sesuai dengan peruntukannya, seperti bahan baku air minum, prasarana/sarana rekreasi, industri, peri-

\section{Cite this as:}

Fitria, L., Desmaian, H., Marcelina, M., Syafrianto, K., \& Khairi, S. (2020). Status Mutu Air pada Lahan Gambut di Sungai Putat Kota Pontianak Kalimantan Barat. Rekayasa, 13(1), 45-48. doi: https://doi.org/10.21107/rekayasa.v13i1.5920

(c) 2020 Author(s) 


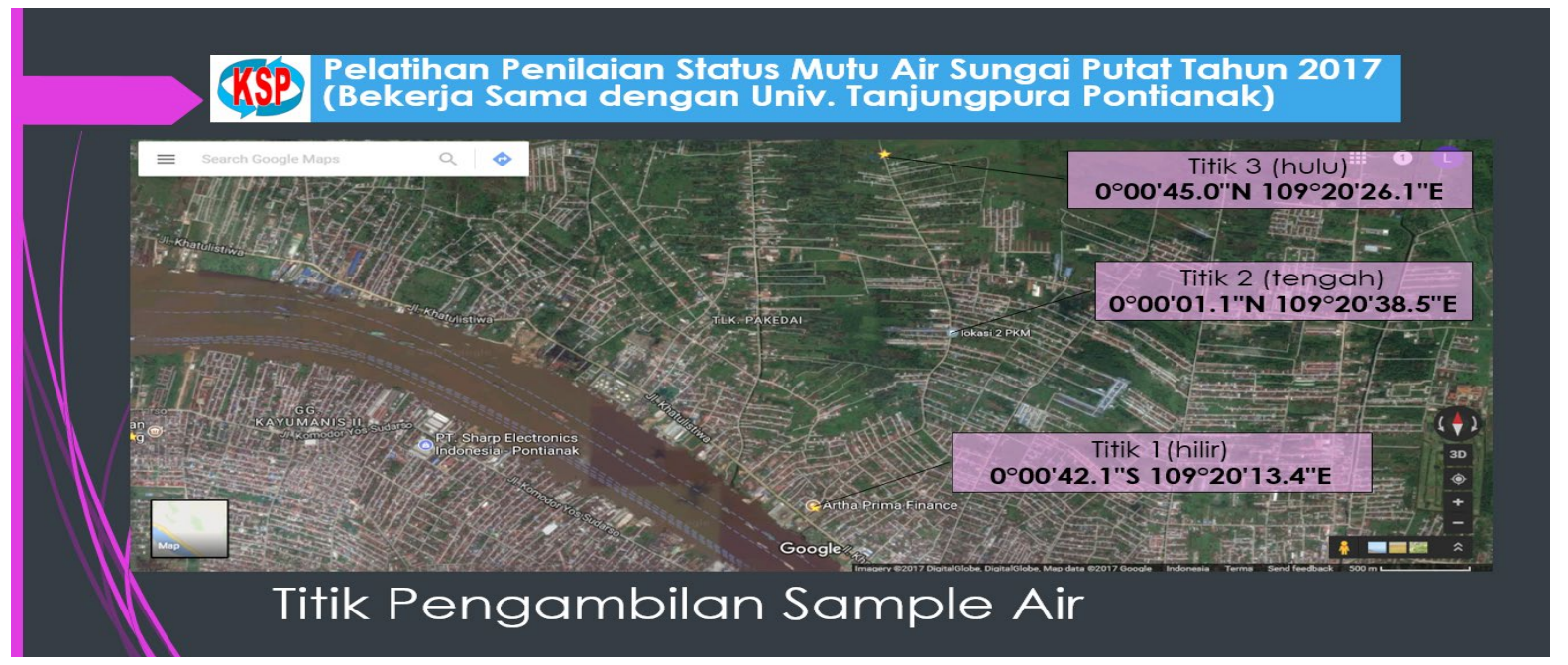

Gambar 1. Lokasi Titik Pengambilan Sample Air

kanan, peternakan dan pertanian. Suatu perairan dikatakan telah tercemar apabila beban pencemarnya telah melampaui kriteria baku mutu air yang ditentukan dalam Peraturan Pemerintah Nomor 82 Tahun 2001. Kondisi ini bila tidak dikelola dengan baik akan segera menimbulkan dampak yang negatif terhadap masyarakat Kota Pontianak (Yulistiana, 2007), khususnya di Sungai Putat.

Sehingga perlu dilakukan penelitian terhadap Status Mutu Air Sungai di Sungai Putat Kota Pontianak untuk mengevaluasi terjadinya perubahan lingkungan. Pada penilaian status mutu ini, standar yang digunakan adalah mutu air bersih (air kelas II sesuai PP 82 tahun 2001). Dengan mengetahui status mutu air, bisa digunakan sebagai early warning system terhadap kualitas air bersih.

\section{METODE PENELITIAN}

Penelitian ini dilakukan di Sungai Putat yang berada di Kelurahan Siantan Hilir Kecamatan Pontianak Utara Kota Pontianak Provinsi Kalimantan Barat. Pengambilan sample air sungai dilaksanakan pada bulan Mei 2017. Teknik pengambilan sampel air mengacu pada SNI 6989.57 Tahun 2008 Tentang Metoda Pengambilan Contoh Air Permukaan. Uji kualitas air mengacu pada PP Nomor 82 Tahun 2001 Tentang Pengelolaan Kualitas Air dan Pengendalian Pencemaran Air. Standar yang dipilih adalah Kelas II sesuai dengan peruntukan air sungai di Sungai Putat, yakni sebagai air bersih.

Alat dan bahan yang digunakan pada penelitian ini yaitu bak ukur untuk mengukur kedalaman parit, GPS (Global Positioning System) untuk mengetahui koordinat titik lokasi pengambilan sampel air sungai, pita ukur untuk mengukur lebar Sungai Putat. Untuk perhitungan debit dilakukan secara manual yakni dengan menggunakan kecepatan bola/pelampung. Selain itu juga dibutuhkan stop- watch untuk mengukur waktu, botol sample air sebagai wadah sample air, termometer untuk mengukur suhu pada sample air, pelampung untuk mengukur kecepatan arus air, cooling box sebagai wadah pengawetan sampel, serta alat tulis untuk mencatat data di lapangan.

Pengambilan sampel pada air di saluran primer diambil dengan cara pengambilan sampel sesaat (grab sampling) sesuai dengan SNI 06-2412-1991. Sampel sesaat atau grab sampling yaitu sampel yang diambil secara langsung dari badan air yang sedang dipantau kualitasnya. Sampel ini hanya menggambarkan karakteristik kualitas air pada saat pengambilan sampel air tersebut (Effendi, 2003). Pengambilan sampel dilakukan di beberapa titik. Debit sungai diukur terlebih dahulu kemudian ditentukan jumlah titik pengambilan sampel.

Di sepanjang aliran Sungai Putat terdapat aktivitas masyarakat yang menghasilkan limbah dan mengalir ke Sungai Putat, antara lain terdapat lokasi tempat pencucian motor, area pertanian, perkebunan, bengkel serta mandi cuci kakus (MCK). Titik pengambilan sample air yaitu bagian hulu, tengah dan hilir dari Sungai Putat.

Kondisi bagian hulu Sungai Putat merupakan lahan gambut yang masih semak dan sebagian digunakan untuk pertanian. Bagian tengah terletak di tengah pemukiman penduduk, selain itu lahan digunakan untuk aktivitas pemukiman dan pertanian. Kondisi existing pada bagian hilir, lahan digunakan untuk pemukiman dan terdapat pemakaman umum.

Uji kualitas air sungai berguna untuk mengetahui kadar pencemar di perairan tersebut. Parameter yang diuji adalah $\mathrm{pH}$, oksigen terlarut (Dissolved Oxygen), residu tersuspensi, BOD5, COD, total fosfat, nitrat, nitrit, amoniak dan total coliform. 
Analisis data meliputi kualitas air, perhitungan debit air di saluran primer, analisis status mutu air. Berikut merupakan beberapa persamaan yang digunakan untuk mendukung analisis sampel : Perhitungan debit menggunakan persamaan :

$$
\mathrm{Q}=\mathrm{A} \cdot \mathrm{V}
$$

dengan, Q : Debit (m3/dtk)

A : Luas penampang basah saluran (m2)

$\mathrm{v}$ : Kecepatan arus (m/dtk)

Penentuan status mutu air sungai Putat dilakukan dengan metode STORET. Secara prinsip metode STORET adalah membandingkan antara data kualitas air dengan baku mutu air yang disesuaikan dengan peruntukannya guna menentukan status mutu air. Cara untuk menentukan status mutu air adalah dengan menggunakan sistem nilai dari "US-EPA (Environmental Protection Agency)" dengan mengklasifikasikan mutu air dalam empat kelas, yaitu :

1. Kelas A : baik sekali, skor $=0 \rightarrow$ memenuhi baku mutu

2. Kelas $B$ : baik, skor $=-1 \mathrm{~s} / \mathrm{d}-10 \rightarrow$ cemar ringan

3. Kelas $\mathrm{C}$ : sedang, skor $=-11 \mathrm{~s} / \mathrm{d}-30 \rightarrow$ cemar sedang

4. Kelas D : buruk, skor $\geq-31 \rightarrow$ cemar berat

Penentuan status mutu air dengan menggunakan metoda STORET dilakukan dengan langkah sebagai berikut : (1) Lakukan pengumpulan data kualitas air dan debit air secara periodik sehingga membentuk data dari waktu ke waktu (time series data). (2) Bandingkan data hasil pengukuran dari masing-masing parameter air dengan nilai baku mutu yang sesuai dengan kelas air. (3) Jika hasil pengukuran memenuhi nilai baku mutu air (hasil pengukuran < baku mutu) maka diberi skor 0. (4) Jika hasil pengukuran tidak memenuhi nilai baku mutu air (hasil pengukuran > baku mutu), maka diberi skor seperti pada Tabel 1. (5) Jumlah negatif dari seluruh parameter dihitung dan ditentukan status mutunya dari jumlah skor yang didapat dengan menggunakan sistem nilai.

Tabel 1. Penentuan sistem nilai untuk menentukan status mutu air (Menteri Negara Lingkungan Hidup Republik Indonesia, 2003)

\begin{tabular}{llccc}
\hline \multirow{2}{*}{ Jumlah Contoh* } & \multirow{2}{*}{ Nilai } & \multicolumn{3}{c}{ Parameter } \\
& & Fisika & Kimia & Biologi \\
\hline$<10$ & Maksimum & -1 & -2 & -3 \\
& Minimum & -1 & -2 & -3 \\
& Rata-rata & -3 & -6 & -9 \\
\multirow{2}{*}{10} & Maksimum & -2 & -4 & -6 \\
& Minimum & -2 & -4 & -6 \\
& Rata-rata & -6 & -12 & -18
\end{tabular}

keterangan: *) jumlah parameter yang digunakan untuk penentuan status mutu air

\section{HASIL DAN PEMBAHASAN}

Menurut Peraturan Pemerintah Nomor 82 Tahun 2001 Tentang Pengelolaan Kualitas Air dan Pengendalian Pencemaran Air, air Sungai Putat termasuk air klasifikasi mutu air kelas 2, hal ini dikarenakan air dapat digunakan untuk prasarana/sarana rekreasi air, pembudidayaan ikan air tawar, peternakan, untuk mengairi pertanaman, dan peruntukkan lainnya. Sehingga hasil uji kualitas air Sungai Putat dapat dibandingkan dengan baku mutu air kelas II yang dapat dilihat pada Tabel 2.

Berdasarkan tabel 2, maka dapat diketahui bahwa parameter $\mathrm{pH}$ titik 1 dan titik 2 tidak memenuhi kriteria mutu air kelas II. Keasaman gambut terjadi karena adanya senyawa fenolat dan karboksilat dari proses dekomposisi bahan organik pada lahan gambut. Kemasaman tanah gambut tropika umumnya tinggi ( $\mathrm{pH}$ 3-5), disebabkan oleh buruknya kondisi pengatusan dan hidrolisis asamasam organik, yang didominasi oleh asam fulvat dan humat (Widjaja-Adhi, 1988; Rachim, 1995 dalam Dariah, Maftuah, \& Maswar, 2013). Sehingga pada parameter $\mathrm{pH}$, nilai yang dihasilkan bersifat asam. Derajat keasaman yang rendah ini dikarenakan pada titik 1 (Hulu) dan titik 2 (tengah), jenis tanah di lokasi tersebut adalah tanah gambut. Tanah gambut mempengaruhi $\mathrm{pH}$ dalam suatu perairan menjadi rendah atau cenderung asam.

Parameter COD dan total fosfat sebagai $P$ pada titik 1, titik 2 dan titik 3 tidak memenuhi kriteria mutu air kelas II. Hal ini dikarenakan adanya limbah domestik atau pembuangan hasil toilet, limbah rumah tangga dan industri yang terdapat di

Tabel 2. Perbandingan Hasil Uji dengan Baku Mutu Air Kelas II

\begin{tabular}{|c|c|c|c|c|c|c|}
\hline No. & $\begin{array}{c}\text { Parameter } \\
\text { Uji }\end{array}$ & $\begin{array}{l}\text { Satu- } \\
\text { an }\end{array}$ & $\begin{array}{l}\text { Titik } 1 \\
\text { (Hulu) }\end{array}$ & $\begin{array}{c}\text { Titik } 2 \\
\text { (Tengah) }\end{array}$ & $\begin{array}{l}\text { Titik } 3 \\
\text { (Hilir) }\end{array}$ & $\begin{array}{c}\text { Kriteria } \\
\text { Mutu Air } \\
\text { Kelas II } \\
\text { (PP No.82 } \\
\text { Tahun } \\
\text { 2001) }\end{array}$ \\
\hline 1 & $\mathrm{pH}$ & - & 4,0 & 5,2 & 6,3 & $6-9$ \\
\hline 2 & DO & $\mathrm{mg} / \mathrm{L}$ & 4,9 & 7,5 & 7,6 & Min. 4 \\
\hline 3 & $\begin{array}{l}\text { Residu } \\
\text { Tersuspensi }\end{array}$ & $\mathrm{mg} / \mathrm{L}$ & 0,4 & 11,2 & 8 & Maks. 50 \\
\hline 4 & $\mathrm{BOD}_{5}$ & $\mathrm{mg} / \mathrm{L}$ & 0,4 & 0,65 & 2,63 & Maks. 3 \\
\hline 5 & COD & $\mathrm{mg} / \mathrm{L}$ & 91,2 & 90,3 & 92,1 & Maks. 25 \\
\hline 6 & $\begin{array}{l}\text { Total fosfat } \\
\text { sebagai } P\end{array}$ & $\mathrm{mg} / \mathrm{L}$ & 0,999 & 1,43 & 1,17 & Maks. 0,2 \\
\hline 7 & $\begin{array}{l}\text { Nitrat } \\
\text { sebagai } \\
\mathrm{NO}_{3}-\mathrm{N}\end{array}$ & $\mathrm{mg} / \mathrm{L}$ & 3,47 & 2,16 & 1,89 & Maks. 10 \\
\hline 8 & $\begin{array}{l}\text { Nitrit } \\
\text { sebagai } \\
\mathrm{NO}_{2}-\mathrm{N}\end{array}$ & $\mathrm{mg} / \mathrm{L}$ & 0,019 & 0,024 & 0,038 & Maks. 0,06 \\
\hline 9 & $\begin{array}{l}\text { Amoniak } \\
\text { sebagai } \\
\mathrm{NH}_{3}-\mathrm{N}\end{array}$ & $\mathrm{mg} / \mathrm{L}$ & 0,003 & 0,102 & 1,74 & - \\
\hline 10 & $\begin{array}{l}\text { Total Coli- } \\
\text { form }\end{array}$ & $\begin{array}{l}\text { Koloni/ } \\
100 \mathrm{~mL}\end{array}$ & 610 & 140 & 70 & Maks. 5000 \\
\hline
\end{tabular}


48 | Fitria, L., dkk, Status Mutu Air pada Lahan Gambut di Sungai Putat ..

sepanjang tepian Sungai Putat. Limbah yang dihasilkan akan mempengaruhi kadar COD suatu perairan. Kadar COD dipengaruhi oleh reaksi oksidasi yang terjadi di dalam air. Reaksi ini merupakan penambahan atau pengikatan oksigen oleh suatu unsur atau senyawa. Secara umum faktor lingkungan yang mempengaruhi konsentrasi COD pada air tanah dapat dikategorikan sebagai sumber kontaminan langsung dan tidak langsung. Sumber langsung meliputi efluen yang keluar dari industri, dan sebagainya. Sumber tidak langsung yaitu kontaminan yang memasuki badan air dari tanah, air tanah, atau atmosfer berupa hujan. Tanah dan air tanah mengandung sisa dari aktivitas pertanian seperti pupuk dan pestisida. Kontaminan dari atmosfer juga berasal dari aktivitas manusia yaitu pencemaran udara yang menghasilkan hujan asam. Hasil penelitian serupa juga menunjukkan hal yang sama, yakni nilai COD bernilai tinggi akibat adanya buangan limbah domestik akibat pemukiman. Sementara, nilai COD melebihi standar baku mutu di bagian hulu, akibat proses eutrofikasi (Pramaningsih, Suprayogi, \& Setyawan Purnama, 2017).

Parameter Total Fosfat pada titik 1, titik 2 dan titik 3 tidak memenuhi kriteria mutu air kelas II. Hal ini dikarenakan terdapat aktivitas pertanian pada bagai hulu dan pertengahan sekitar Sungai Putat. Penggunaan pupuk oleh petani setempat mempengaruhi Total Fosfat yang terdapat di perairan tersebut. Penggunaan detergen hasil dari limbah rumah tangga juga mempengaruhi kadar Total Fosfat menjadi tinggi.

Penentuan status mutu air sungai menggunakan metode STORET. Menurut Keputusan Menteri Negara Lingkungan Hidup Nomor 115 Tahun 2003 Tentang Pedoman Penentuan Status Mutu Air, prinsip dari metode STORET adalah membandingkan antara data kualitas air dengan baku mutu air yang disesuaikan dengan peruntukannya guna menentukan status mutu air. Cara untuk menentukan status mutu air adalah dengan menggunakan sistem nilai dari "US-EPA (Environmental Protection Agency)" dengan mengklasifikasikan mutu air dalam empat kelas. Berdasarkan perhitungan menggunakan metode STORET, perairan Sungai Putat memiliki skor -28. Hasil skor tersebut dapat dikatakan bahwa Sungai Putat tercemar sedang.

\section{KESIMPULAN DAN SARAN}

Berdasarkan hasil penelitian, diketahui bahwa status mutu Sungai Putat menggunakan metode STORET memiliki skor -28. Hasil skor tersebut dapat dikatakan bahwa Sungai Putat tercemar sedang. Parameter yang melebihi baku mutu, antara lain $\mathrm{pH}, \mathrm{COD}$, dan total Fosfat sebagai P. Diperlukan penelitian lanjutan mengenai status mutu sungai di Kawasan gambut lainnya, serta adanya pengambilan sample air dengan waktu berkala. Selain itu, juga bisa dilakukan perhitungan status mutu air dengan metode lainnya sebagai pembanding.

\section{DAFTAR PUSTAKA}

Dariah, A., Maftuah, E., \& Maswar. (2013). Karakteristik Lahan Gambut. Panduan Pengelolaan Berkelanjutan Lahan Gambut Terdegradasi, 16-29.

Effendi, H. (2003). Telaah Kualitas Air: Bagi Pengelolaan Sumber Daya Alam dan Lingkungan Perairan. Yogyakarta: Penerbit Kanisius.

Fulazzaky, M.A, Seong, T.W., dan Masirin, M. I. M. (2010). Assessment of Water Quality Status for The Selangor River in Malaysia. Water Air Soil Pollution, 205, 63-77.

Hendrawan, D. (2005). Kualitas Air Sungai dan Situ di DKI Jakarta. MAKARA, 9(1), 13-19.

Liu, Zhi Jun, Wller, Donald E., Jordan, Thomas E., Correll, David L., Boomer, K. B. (2008). Integrated Modular Modeling of Water and Nutrients from Point and Nonpoint Sources in The Patuxent River Watershed. Journal of American Water Resources Association, 44(3), 700-723.

Menteri Negara Lingkungan Hidup Republik Indonesia. (2003). Keputusan Menteri Negara Lingkungan Hidup No. 115 tahun 2003 tentang Pedoman Penentuan Status Mutu Air.

Pramaningsih, V., Suprayogi, S., \& Setyawan Purnama, I. L. (2017). Kajian Persebaran Spasial Kualitas Air Sungai Karang Mumus, Samarinda, Kalimantan Timur. Jurnal Pengelolaan Sumberdaya Alam Dan Lingkungan (Journal of Natural Resources and Environmental Management), 7(3), 211-218. https://doi. org/10.29244/jpsl.7.3.211-218

Yulistiana, L. (2007). Penentuan Kualitas Air dan Kajian Daya Tampung Sungai Kapuas, Kota Pontianak. IPB. 